\title{
DOUBLE ADHESIVE FILM: AN ADJUNCT TO STETHOSCOPE MONITORING
}

\author{
A. C. WEBSTER, M.B., CH.B., F.F.A.R.C.S., F.R.C.P.(C)
}

THE PURPOSE OF MONITORING in clinical anaesthesia is to increase patient safety by extending the range and acuity of the anaesthetist's senses. The value of monitoring equipment in routine clinical anaesthesia is inversely proportional to its complexity if, with increasing complexity, the anaesthetist's attention is increasingly diverted from the patient to the apparatus. As the use of electrical devices in the operating room proliferates, increasingly serious hazards are encountered.

No monitoring device gathers relevant information more simply, safely, reliably, and economically, than the stethoscope. Contact with the patient is maintained and attention is directly focused on vital organ systems. Particularly in paediatric anaesthesia, continuous auscultation of heart sounds and breath sounds by precordial stethoscope is widely acknowledged to represent a minimum standard of patient care. Efficient continuous stethoscope monitoring is facilitated by the monaural ear piece which, for comfort and optimum sound conduction, should be individually moulded. ${ }^{1}$ A plastic three way stop-cock and tubing with Luer connectors allows rapid interchange between precordial or oesophageal and brachial transducers.

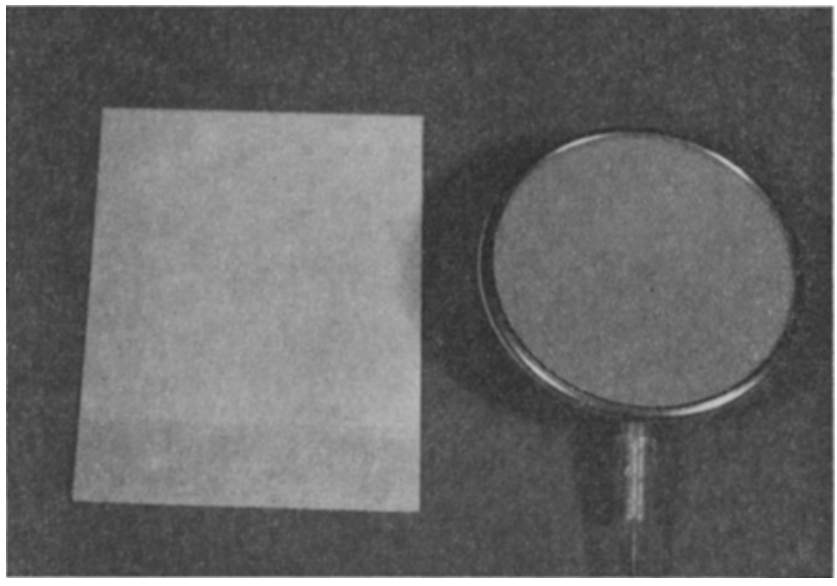

Figure 1. Stethoscope diaphragm and square of double adhesive film.

The efficiency of the stethoscope transducer is influenced by its physical characteristics and its method of attachment. It is surprising that for such fundamental equipment, there is so little research into optimum design. For example, the resonance of commercially available diaphragms is so variable that conduction of sound from some is negligible. An epoxy fibreglass disc secured by a screw on metal ring has been found to be a satisfactory, inexpensive and durable transducer. ${ }^{2}$ 


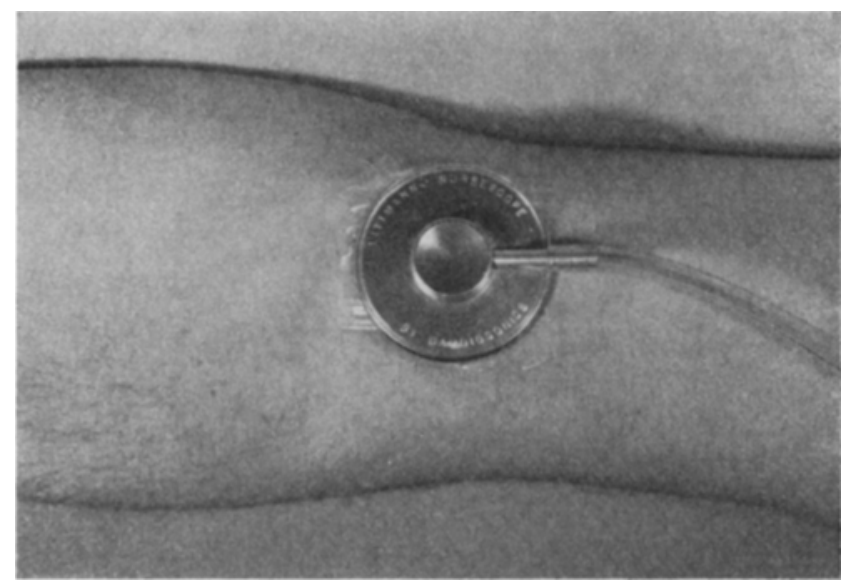

FIGURE 2. Stethoscope applied with adhesive film.

When the transducer is attached by conventional adhesive tape, transmission of sound may be less than ideal when the area of contact between diaphragm and skin is incomplete, or when it is taped too firmly, vibration may be damped. A double coated pressure sensitive adhesive film ${ }^{3}$ has been found to be ideal. The material is supplied as two-inch squares with two liners, one projecting beyond the other. One liner is peeled away and the adhesive surface applied to the diaphragm. The second liner is then peeled away and the diaphragm attached to the skin, which should be dry. Unduly oily skin should be prepared with alcohol and dried, or with an adhesive aerosol such as Tincture of Benzoin.

\section{SUMMARY}

A double coated pressure sensitive adhesive is described which, by facilitating attachment of the stethoscope diaphragm, increases its usefulness in operating room monitoring.

\section{REFERENCES}

1. Ploss, R. H. A Simple Constant Monitoring System, Anesthesiology, 16: 466 (1965).

2. Litrman, Nursescope Diaphragm Stethoscope; 3M Company, Medical Products Division.

3. Double coated pressure sensitive stethoscope adhesive. Seal-on-Products, A Division of Kraft Tapes Limited, 1165 Frances Street, London, Ontario. 